\title{
Mapping the Te Reo Māori Translation Ecosystem: A Socio-Economic Perspective
}

\begin{abstract}
The increased use of te reo Māori by the government and the corporate sector in Aotearoa has created numerous opportunities for te reo translators who are engaged to translate voluminous te reo Māori documents, websites and apps, digital and social media messages and public signage which have been proliferated in recent times. These translation works represent significant economic activity as te reo Māori translators are awarded contracts valued at thousands of dollars. The economic eco-system created by the increased opportunities in the use of te reo Māori translation is a dynamic one that requires detailed study and attention from te reo scholars given the need for quality assurance and maintenance of the standards of the language. To set the backdrop for the paper a literature review on the history and development of te reo Māori translation will be presented. The historical antecedents of the te reo Māori translation economy will be traced and highlighted as the springboard for the current state of the te reo Māori translation economy which will then be discussed. An in-depth analysis of the licensing process for te reo Māori translators will be presented and arguments for an expanded role of $\mathrm{Te}$

Hēmi Kelly (Ngati Maniapoto and Ngati Tahu-Ngati Whāoa) is a Lecturer in te reo Māori at Auckland University of Technology. His academic research and writing focus on the revitalisation of the Maori language and translation studies. Andre Poyser has a Master of Applied Finance from Auckland University of Technology. His research project was titled Indigenous Investment Frameworks: Lessons from Iwi-A Case Study of Tainui Group Holdings.
\end{abstract}


Taura Whiri i te Reo Māori in providing oversight of translation contracts will be made. We will present a theoretical framework for the economic considerations surrounding the te reo Māori translation ecosystem and provide a narrative and schematic description of a te reo Māori translator's work as a paid economic activity. In doing this we shed light on the growing economic importance of te reo Māori.

Key Words: language revitalization, translation, te reo Māori, language economics

\section{Introduction}

There is an increasing acceptance of the fundamental elements of Māori culture - in particular, the normalisation of te reo Māori in the business world and the wider society (Kelly, 2018). While contentious arguments continue to be made about the small percentage of te reo Māori speakers and the relevance of teaching the language, the growth in the use of the written language has almost gone unacknowledged. It is our contention that an economic case can be made for the traslatory use of the language given that te reo Māori consultants and translators have to be engaged to undertake translation of the voluminous te reo Māori documents, websites and apps, digital and social media messages and public signage which have been proliferated in recent times; see Whaanga,Keegan and Apperley (2017), Roa (2004), Reedy (2000), Manuirirangi (2017), Keegan et al (2015). The fact is that the engagement of these translators comes at a cost and the value of some translation contracts can be quite significant.

At the time of writing there were some 133 registered te reo Māori translators and interpreters in the general and education register of Te Taura Whiri i te Reo Māori-the Māori Language Commission (Maori Language Commission , 2019). Of this number $48 \%$ were conferred 
with both Māori translators and interpreters license, having passed the 15 (2) (c) oral and written exam offered by the Commission while 15 per cent held only the translators license issued for the 15 (2) (b) written exam. For our purposes, this means that the Commission's register comprises 63 per cent of translators. The aim of this paper is to map the economic contribution of these translators through a descriptive analysis of their work. While it is beyond our scope to quantify and assign a dollar figure to the te reo Māori translation economy, it is our hope that this paper can serve as a spring board for such an undertaking. From the growth in the use of te reo Māori we know that significant sums are being earned by translators and this calls for critical analysis of the te reo Māori translation sector in respect of costing of contracts and maintenance of quality standards. The reminder of the paper will be organized as follows. The next section presents a literature review on the history and development of te reo Māori translation. In Section 3 we present a theoretical framework for the economic considerations surrounding the te reo Māori translation ecosystem while Section 4 provides a narrative and schematic description of a te reo Māori translator's work as a paid economic activity. Finally, reflections and conclusions are presented.

\section{Literature Review}

One of the main reasons for language revitalization among indigenous peoples relates to the human rights issues embedded in the larger struggle against oppression and counteracting the impacts of colonization (McCarty, 2003). The Māori, the indigenous people of Aotearoa New Zealand, represent, perhaps, the best practice among indigenous people in this regard. Beginning with the Māori Language Claim at the Waitangi Tribunal, te reo Māori is now experiencing a resurgence because of the tireless efforts of Māori activists who raised alarm about the virtual death of the language due 
to the impacts of colonization (Benton, 1989). The te reo Māori claim, among other demands, called for te reo Māori to be declared an official language. The impact of this has seen the language being used across all government departments, public signage, in the translation of official and court documents and proceedings, in print, broadcast and social media. The role of translators in the revitalization efforts of te reo Māori and the growing prominence of the language nationally has been and continues to be a critical one.

This significant push for language revitalization was codified in several iterations of the Maori Language Revitalization Strategy, the first of which was approved by the Cabinet and promulgated in 2003. The strategy is based on theories of Reverse Language Shift (RLS), which focuses on initiatives which seek to change behaviours, attitudes and beliefs about a threatened language (Fishman, 1991). A key question raised in the literature is whether or not it is the state's responsibility to protect a threatened language, particularly if it is not the dominant language or the language of commerce.

Indeed, questions such as these formed the basis of the major objections that were raised against the call for the recognition of te reo Māori as an official language of New Zealand. According to the objectors, minority languages, it would appear, are destined for slow steady deaths as was the case with the Gaelic language in Ireland. However, the survival of many other minority languages around the world through concerted revitalization efforts of the respective governments provides ample evidence that this is an area of cultural preservation in which governments do have a role to play, particularly in respect of safeguarding the language rights of its indigenous populations. Studies of language revitalization efforts among the Cherokee Nation of Oklahoma (Lizette, 2003) and the Suba people of Kenya (Obiero, 2008) highlighted the role of the state in ensuring the successful revitalization of these indigenous languages. Additionally, a national study of Native 
American languages concluded that revitalization of native languages has significant implications for state and national education policies and minority language rights (Romereo-Little, et al., 2007). Other research on successful language revitalization initiatives which benefited from state support includes those of Navajo, Puerto Rican Spanish and Yiddish in New York, Que`be“cois French, Otomi', Quechua, Irish, Frisian, Basque, Catalan, Oko, Andamanese, Ainu, Hebrew, Australian immigrant and indigenous languages, see Garcia, Morin and Rivera (2001); Bourhis (2001); Lastra (2001); Homerger and King (2001); Riagain (2001); Gorter (2001); Azurmendi et al (2001); Strubell (2001); Abegbija (2001); Maher (2001); Spolsky and Shohamy (2001); Clyne (2001); Bianco and Rhydwen (2001).

A key factor in the successful rehabilitation of these indigenous languages has been the role that translators have played in bridging the divide between the dominant language and the endangered language. This is highlighted by the fact that often times some of the most ardent advocates and contributors to language revitalization efforts are not themselves native speakers of the language (Speas, 2009) (Rice, 2009) (Kroskrity, 2009) and as such it is translators who serve as the gateway between the languages and what the literature has described as the ideological struggle in language renewal, see Hinton and Hale (2001); Dauenhauer and Dauenhauer (1998); Hill (2002); Anderson (1998); Meek (1997); Kroskrity and Field (2010).

The ideological struggle between indigenous and colonial languages and the role that translators play in it is uncannily reflected in the Treaty of Waitangi, New Zealand's seminal founding document. The fact that a te reo Māori and English Language version of the document exists and that the meaning assigned to particular words in both differ, indicate the delicate role that Māori translators have in negotiating the power relations between the languages. The case for the te reo Māori claim hinged on the fact that the English translation of 
the treaty did not capture the essence of the Māori word Taonga (teasures) which in Māori encapsulates intangible items of value which extended beyond the physical items translated into the English version. This case was argued convincingly by treaty expert Professor Hirini Moko Mead in his submissions to the Waitangi Tribunal. According to Mead's interpretation of articles two and three of the treaty, the English translation of these articles was not faithful to the Māori meaning and worldview which they would have been based on (Waitangi Tribunal, 1989). The language and the translation thereof, therefore, saved itself, and highlights further the primacy of translation and the work of translators in the onging struggle for Māori language rights.

Second language speakers of endangered languages are the life-blood of language revitalization efforts and this has proven to be the case for te reo Māori where a majority of proficient speakers are second language speakers of the indigenous language (King, 2009). Based on the demographic makeup of the Maori Language Commission's translator's registry, it is not farfetched to conclude that a majority of te reo Māori translators are also second language speakers of te reo Māori (Maori Language Commission , 2019). The motivations which drive second language speakers who have sought to be trained and registered as translators of te reo Māori include a quasi-religious worldview, new age humanism, connection with ancestors and Māori culture and Kaupapa Māori philosophy (King, 2009). The lead author of this paper, a second language speaker of te reo Māori, notes that his motivation for seeking training and certification as a translator came from his desire to connect with the culture of his grandparents who were native speakers of the language (Kelly, 2018).

While second language speakers and by extension translators, play a vital role in the efforts to resuscitate the Māori language, King (2009) in her research, of a sample of 32 Māori informants identified as second language speakers of te reo Māori, found that the 
informants did not see themselves as part of the language revitalization efforts which have been sanctioned by the New Zealand Government. King also found that a larger sense of moral responsibility to the survival of the indigenous language was also lacking among the participants and that their motivations for leaning te reo Māori was integrative rather than instrumentive (King, 2009). When extended to translators, as second language speakers, this raises the question of whether the motivations which drive translators have implications for issues of quality and maintenance of standards in the translation of te reo Māori. This is even more so given the financial benefits which accrue from translation work. Adding economic and career incentives to the list of motivations identified earlier as the driving forces for translators, presents a new narrative of te reo Māori's resurgence which considers the economic contribution of language revitalization efforts in New Zealand. This economic narrative, as it relates to te reo Māori, particularly in regard to the work of translators, is one on which the literature has been silent. The economic value creation associated with language usage and language skills is a growing area of research interest in academia and has been formalized in a body of work that has come to be known as language economics. It is our contention that the te reo Māori translation economy is one that is ideally positioned for placement and research in the field of language economics and this will form the basis of our theoretical framework. An economic narrative of te reo Māori has to, however, take into consideration the historical antecedents which have fostered the socioeconomic ecosystem of te reo Māori translation. This is particularly important, given the need for decolonising the narrative around the economic value of te reo Māori viz a viz English as the language of oppression and colonization (Anaru, 2011). 


\section{Historical Antecedents of the Te Reo Māori Translation Economy}

For Māori, whose language and culture were brought to near extinction by the colonial government, the responsibility of the state in righting the historical wrongs extend to the protection of the Mãori language; an argument that was stridently made by the claimants who brought the te reo Māori claim before the Waitangi Tribunal. As highlighted in the hearings on the claim, the need for affirmative action in respect of te reo Māori came about because of the discriminatory nature of educational policy, media practice and work place policy (Waitangi Tribunal , 1989). The language was banned in schools, prohibited in many work places and was scarcely utilized in broadcast and print media. Pioneering work by Dr. Richard Benton in 1974 provided empirical evidence of the perilous decline of the Māori language and along with a petition, by the Te Reo Māori Society, calling for the introduction of Māori language in schools set the stage for the Māori language claim and the present infrastructure of the Māori language system which grew out of that (Te Rito, 2008). This infrastructure includes the passage of the Māori Language Act of 1989, establishment of the Māori Language Commission, Māori language education programmes across all levels of the education sector and the proliferation of print, radio and television stations dedicated to the broadcasting of te reo Māori content, see Timutimu, Ormsby-Teta and Ellis (2009) and Te Rito (2008).

It could be argued that the erosion of the Māori language was accelerated by the way in which it was treated in the education system. In 1913, 90 per cent of Māori school children could speak te reo Māori, a figure which fell to 5 per cent in 1975 (Benton, 1989). Although there was no official policy banning the use of te reo Māori, Māori students were forbidden from speaking the indigenous language as it was seen as inferior to English. While the practice of forbidding the speaking of te reo Māori in schools was discriminatory and racist in its 
orientation, the insistence on the need for Māori children to master the use of English which had become the dominant language due to the dwindling Māori population was based on the practical realities of what was seen as a greater assimilation of the Māori and European population that was taking place with the rapid urbanization and policy of economic liberalization which the New Zealand Government had embraced at the turn of the century.

The education sector, therefore, became the site of contestation for the Māori language and through what Te Tito (2008) has described as a political act of Māorithe withdrawal of Māori children from the mainstream education system and enrolment in Kohanga Reo (Language Nests) schools- a movement to revive the language had developed and grown into a national effort. The role of the kohanga reo movement in grooming an entire generation of second language te reo Māori speakers and would be translators cannot be overstated. The Kohanga operated as pre-schools where toddlers were cared for in a bilingual environment. Kamātua (elders) who were fluent speakers of te reo Māori were utilized in the Kohanga as primary transmitters of the language to the children. By speaking and interacting with them in the native language, language acquisition among an increasing number of Māori children increased significantly. The Kohanga was deeply rooted in Māori spirituality and custom and as such was more than a means of improving the speaking of the language among Māori but was also a platform for the transfer of the cannons of Māori heritage to the next generation. Through interactive stimulation using Māori art and cultural artefacts, Māori children became exposed to the cosmological and epistemological foundations of the language (Reedy, 2000). The Kohanga movement in the beginning was funded exclusively by Māori and supported by an extended family of aunts and uncles who provided a nurturing environment where the language and culture could be transmitted with ease and with 
maximum effect. Beginning in 1981 by self-funded small family groupings in Wellington, today the Kohanga movement is part of the formal education system and receives Government funding from the early-childhood budget. There are now over 1000 licensed Kohanga centers immersing thousands of Māori and non-Māori children in the love and beauty of te reo Māori (Reedy, 2000). Kohanga Reo has been described as one of the most effective methods of indigenous language and cultural acquisitions for the future generations of indigenous populations (Kirkness, 1998).

Out of concern for the fact that a lack of continued engagement with the language at the primary level would result in language loss among the toddlers who were given a Kohanga education, Karu Kaupapa Māori (Total Immersion School) was established in 1985 as schools which provided primary level education. These also garnered the support of the Government and are based on similar Māori philosophies as the Kohanga. Secondary schools and programmes at the tertiary level were also introduced as a natural progression of the proliferation of the language in the education system (Reedy, 2000). These historical events, particularly in the education system, are the foundation of the te reo Māori translation economy as they have provided the crucible from which a class of individuals plying their trade as Māori translators has emerged.

\section{Current State of Te Reo Māori and Translation Economy}

Through the affirmative action and activism of Māori, te reo Māori is now considered to be at stage six and in some instances stage three of Fishman's Graded Intergenerational Disruption Scale (GIDS), which contains eight steps through which a reversal of language shift (RLS) can be attained (Benton $\&$ Benton, 2001). Data from national surveys and the census continue to show that knowledge of the indigenous language is strengthening and that the initiatives in education, media 
and at the policy level are beginning to engineer a genuine revival of te reo Māori as a truly national language and culture treasure of New Zealand (Bauer, 2007). The enabling environment that has been created for te reo Māori to thrive has been complimented by the advance of technology and it is in this regard that translators have built up a growing body of paid work around the translation of websites, apps, computer software, games and social media content.

The use of te reo Māori in technology was pioneered by the teaching of a te reo Māori Computer Science course at the University of Waikato in 1993. Since then a plethora of web, mobile and software-based applications have been promulgated by educational institutions, commercial entities, non-profits and individuals (Keegan, Keegan, \& Laws, 2011). These te reo Māori ICT initiatives have come about through the introduction, by the Māori Language Commission, of new words in the Māori language for modern technological devices and concepts. The Te Matatiki dictionary of contemporary Māori words published by The Maori Language Commission in 1996 consisted of 5,500 new words and 3,000 previously unpublished Maori equivalents (Reedy, 2000).

The development and free accessibility of digital Māori language dictionaries have also made it easier for translators to carry out their work in the digital space. Furthermore, the majority of translation work is now taking place in the digital space as the demand for Māori language apps, animation and online resources continues to increase (Kaai, 2017). Māori translation is also being significantly enhanced by the introduction of machine translation software for te reo Māori by Google and Microsoft. While the amount of digitized Māori language data remains minimal, creating inaccuracies in machine translation of te reo Māori, the growth in the use of this technology by translators is undeniable (Keegan T. T., 2017). Even outside of the digital space, the demand for Māori translators is very strong particularly among 
government agencies and corporate New Zealand, which are infusing a greater level of bilingualism in their documents, signage and activities.

The question of how much translators should be paid for their work is one which courts contention as there is yet no standard in this regard (Māori Television, 2018). The monitoring of translation work is fragmentary at best and this suggests a greater role for the Māori Language Commission or some other official body. While there have been several attempts at self-regulation and standardization, the translation industry is one which has remained fragmented. Kāhui Whakamāori, an industry association of translators has recently been formed and it is hoped that this will professionalized the industry (Māori Television, 2018). The thrust of the industry towards a more transparent mode of operation is critical given the advance of computer algorithms in the translation of languages where crowdsourcing of translators has reduced the cost of translation work and the need for expensive professional translators (Gao, Xu, \& Callison-Burch, 2015).

\section{Role of the Māori Language Commission in the Te Reo Māori Translation Economy}

The recognition of te reo Māori as an official language and the attendant changes which that recognition demanded in respect of the use of the language in the courts, Parliament, government departments and agencies paved the way for the emergence of a critical mass of translators through the training and certification efforts of the Māori Language Commission. Those efforts have continued with 60 candidates sitting the Toi Reo Māori Examination last year and 113 sitting the Language Finder Exam. The eleven people who passed the Toi Reo Māori Examination increased the number of translators and interpreters by 20 per cent (Maori Language Commission , 2018).

The commission is currently undergoing significant change with the appointment of a new 
Chairperson and the promulgation of the government's new Māori Language Strategy - the proposed Maihi Karauna. The new strategy, coordination of which has been assigned to the commission, will replace the 2003 strategy which was found to be ineffective by an audit conducted by the Auditor General.

The Commission is authorized under the Māori Language Act 2016 to certify translators. To this end the Commission conducts training courses which covers a wide range of topics including theories, quality criteria, assessments, orthographic conventions, reports for schools, businesses, community et cetera and media releases, advertisements. Courses are held between March and April with examinations taking place in May and December (Maori Language Commission , 2018).

The certification process for translators, as described by the Commission, begins with booking the venue for the sitting of the exam, after which tutors for the delivery of the training courses are engaged and marketing materials regarding the upcoming exams are prepared and disseminated. The promotional activities related to the translator's examination are proceeded by creating of the online registration portal and the subsequent registration of candidates. While registration is ongoing the materials and resources for the training course are created and exam questions are prepared. With registration completed, candidates attend the month-long training course, after which they sit the exam and marking takes place. Candidates are then notified via email of their results and certificates mailed to them. 
Certifying translators process (High level).

\begin{tabular}{|c|c|c|c|c|c|c|c|c|}
\hline Te Amo & $\begin{array}{l}\text { 1. Book } \\
\text { venue }\end{array}$ & $\begin{array}{l}\text { 2. Source } \\
\text { tutors }\end{array}$ & $\begin{array}{l}\text { 3. Prepare } \\
\text { comms }\end{array}$ & $\begin{array}{l}\text { 8. Book travel } \\
\text { and } \\
\text { accommodation }\end{array}$ & $\begin{array}{l}\text { 9. Create } \\
\text { learning } \\
\text { resource }\end{array}$ & $\begin{array}{l}\text { 10. Create } \\
\text { exam } \\
\text { questions }\end{array}$ & $\begin{array}{c}12 . \\
\text { Grading }\end{array}$ & $\begin{array}{l}\text { 13. Update } \\
\text { registered } \\
\text { translator \& } \\
\text { interpreters }\end{array}$ \\
\hline Te Toko & & & $\begin{array}{c}4 . \\
\text { Advertise }\end{array}$ & $\begin{array}{l}\text { 5. Create } \\
\text { Online reg. } \\
\text { form }\end{array}$ & $\begin{array}{l}\text { 6. Attach link } \\
\text { to form in corp. } \\
\text { web }\end{array}$ & & & \\
\hline Applicant & & & & & 7. Register & $\begin{array}{l}\text { 11. Attend } \\
\text { training \& } \\
\text { exam }\end{array}$ & & \\
\hline
\end{tabular}

Fig. 1 Process for certifying translators, source: Māori Language Commission

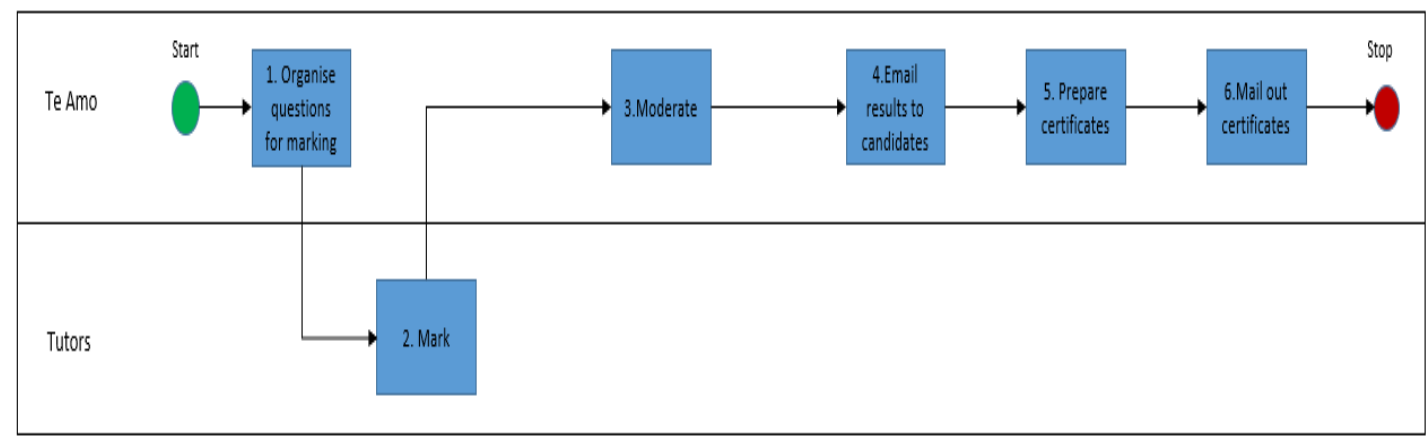

Fig.2 Marking process for translators' exam, source: Māori Language Commission 
While Te Taura Whiri i te Reo Māori engages in a rigorous licensing process, there is no formal system which tracks the awards of te reo Māori translation contracts and provides oversight of the quality of translation work that is produced after the translators have been licenced. In mapping the te reo Māori ecosystem, we seek to highlight the need for greater understanding of the economic value of translation work and also the need for institutional oversight for translation work by Te Taura Whiri i te Reo Māori. The case for greater oversight for translation contracts stems from concerns around maintaining the quality standards of the translation profession and also the need to collect and analyze data on the value of these contracts, the translation process engaged by translators, the organizations issuing these contracts and to whom they are awarded, the costing of contracts and the turnaround time for these contracts.

\section{Theoretical Framework for the Economic Value of Te Reo Maori Translation Work}

The economic value of language is encompassed in the role it plays in facilitating economic relationships and also in its characterization as a form of human capital which endows an individual with the capacity to engage in the production process. Language can therefore be thought of as both an enabler of economic production and as a product of the economic production process itself (Grin, 1994). Despite the philosophical debates, which continue to rage about the difficulty of quantifying what is considered an intangible cultural phenomenon, the field of language economics is gaining popularity and there is a growing body of work, which examines the subject area (Ginsburgh \& Shlomo, 2016).

The Māori language and culture economy has been defined as the aggregate of the goods and services which take as a direct input in their production process, the cultural capital of te reo Māori. The economic value of te reo Māori is therefore the sum total expenditure on te 
reo Māori through production and consumption of te reo Māori products and services. Efforts to determine a dollar value for the te reo Māori economy have up to this point remained inconclusive (Roskruge, Morrison, \& Maxwell, 2017).

The economic value of a language is fundamentally derived from its usage (Gunaruwan \& Kulatunga, 2012) and it is in this respect that translation of te reo Māori and the work of translators has to be considered as the prime enabler of the te reo Māori economy, as without the translation of the language its usage would remain very limited.

The economic value of a language is also derived from the production and consumption of language specific goods and services (Gunaruwan \& Kulatunga, 2012). As argued throughout this paper, the case for translation work as a language specific good and service is indisputable, and the remainder of this paper will provide further support for this by detailing elements of the production process of translation as a language specific good and service.

\section{Narrative and Schematic Description of a te reo Māori Translator's Work as an Economic Activity}

There has been a marked increase in demand for translation work. As the government and corporate sector embrace the use of te reo Māori more translators have been able to secure contracts for translation of corporate and government documents, particularly marketing materials. Most translators are self-employed and gain these translation contracts through personal connections and translation agencies, which bid on and solicit contracts. The popularity of a te reo Māori translator does seem to play a role in their ability to secure contracts as social media has become a prime means through which companies reach out to translators who are popular online.

In New Zealand, translators are usually paid on a per-word basis. Other options include charging per line 
of translated text, per hour or on a project basis. The New Zealand Society of Translators and Interpreters estimates that a skilled translator earns an average of $\$ 360$ a day (based on translating 2,000 words at a rate of 18 cents a word). This sum can vary depending on the languages involved, and whether the translator works with clients directly, or through an agency (New Zealand Society of Translators and Interpreters , 2018).

The production process for te reo Māori translation, and translation work in general, involves reading material from the source language and rewriting it in te reo Māori. This includes researching the meaning of words and terminology using dictionaries and the internet. computer-aided translation tools may also be used. Once this is done a translator may check that the original meaning and feeling of the text is not lost and ensure that technical terms are correctly translated. A te reo Māori translator's work may also involve proofreading and editing other translators' work. It also includes consulting with clients about their translation requirements and giving quotes for their translation services.

\section{Conclusion}

Te reo Māori translation has become an increasing important economic activity as the government and corporate sectors in New Zealand make greater use of the indigenous language. Data and insight is needed on the value of contracts for te reo Māori translation work so that we can understand the economic value of the language and in so doing justify the need for quality assurance for translation products and oversight of translation contracts. 


\section{References}

Anaru, N. (2011, November). A Critical Analysis of the Impact of Colonisation on the Māori Language through an Examination of Political Theory. Master of Arts in Māori Development Thesis Submitted to the Auckland University of Technology. Auckland: Auckland University of Technology .

Bauer, W. (2007). Is the Health of Te Reo Maori Improving?. Te Reo, Vol. 51, 33-73.

Benton, N. (1989). Education, Language Decline and Language Revitalisation: The Case of Maori in New Zealand. Language and Education, 3 (2), 65-82.

Benton, R., \& Benton, N. (2001). RLS in Aotearoa/New Zealand 1989-1999. In J. Fishman, Can Threatened Langauges Be Saved? Reversing Language Shift Revisited: A 21st Century Perspective/Edited by Joshua A. Fishman (pp. 423-450). Clevedon: Multilingual Matters .

Fishman, J. (1991). What is reversing language shift (RLS) and how can it succeed? Journal of Miltilingual and Multicultural Development, 5-36.

Gao, M., Xu, W., \& Callison-Burch, C. (2015). Cost Optimization for Crowdsourcing Translation. Human Language Technologies: The 2015 Annual Conference of the North American Chapter of the ACL (pp. 705713). Denver: Association for Computational Linguistics.

Ginsburgh, V., \& Shlomo, W. (2016). The Palgrave Handbook of Economics and Language. London: Houndmills: Palgrave-Macmillan.

Grin, F. (1994). The Economics of Language: Match or Mismatch? International Political Science Review, 2542.

Gunaruwan, L., \& Kulatunga, S. (2012). Economics of Language Usage and the Impact of Value Origination. Journal of the Royal Asiatic Society of Sri Lanka, 185-197.

Kaai, T. (2017). Te Whare Matihiko o Te Reo -digital tools for the revitalisation of te reo Māori. In H. Whaanga, 
T. T. Keegan, \& M. Apperley, He Whare Hangarau Māori-Language, culture \& technology (pp. 29-34). Hamilton: University of Waikato.

Keegan, P., Keegan, T. T., \& Laws, M. (2011). Online Māori Resources and Māori Initiatives for Teaching and Learning: Current activities, successes and future directions. MAI Review, 1-13.

Keegan, T. T. (2017). Machine translation for te reo Māori.

In H. Whaanga, T. Keegan, \& M. Apperley, He Whare Hangarau Māori-Language, culture \& technology (pp. 23-28). Hamilton: University of Waikato.

Kelly, J. (2018). A Tradition of Māori Translation. The New Zealand Journal of Translation Studies.

King, J. (2009). Langauge is Life: The Worldview of Second Language Speakers of Maori. Indigenous language revitalization: encouragement, guidance \& lessons learned, stabilizing indigenous languages symposium (pp. 97-108). Arizona: Northern Arizona University.

Kirkness, V. (1998). Aboriginal languages: a collection of talks and papers. Vancouver.

Kroskrity, P. (2009). Langauge Renewal as Sites of Lanaguage Ideological Struggle: The Need for Ideological Clarification. Indigenous language revitalization: encouragement, guidance \& lessons learned, stabilizing indigenous languages symposium (pp. 71-84). Arizona: Northern University of Arizona.

Lizette, P. (2003). Assessing the Impact of Total Immersion on Cherokee Language Revitalization: A Culturally Responsive, Participatory Approach. Oklahoma: Northern Arizona University.

Maori Language Commission. (2018). Maori Language Commission Annual Report 2017-2018. Wellington: Maori Language Commission.

Maori Language Commission. (2019). National Translators' and Interpreters' Register. Retrieved from Te Taura Whiri i te Reo Māori: http://www.tetaurawhiri.govt.nz/ourwork/national-translators-register/ 
Māori Television. (2018, September 14). Māori translators push for a set pay rate. Retrieved from Maori Television

News: https://www.maoritelevision.com/news/regional/ maori-translators-push-set-pay-rate

McCarty, T. (2003). Revitalizing Indigenous Languages in Homogenizing Times. In Comparative Education (pp. 147-163).

New Zealand Society of Translators and Interpreters. (2018, December). Spiessl, K, national secretary, Interview. Retrieved from careers.govt.nz.

Obiero, O. (2008). Evaluating Language Revitalization in Kenya: The Contradictory Face and Place of. Nordic Journal of African Studies, 247-268.

Reedy, T. (2000). Te Reo Maori: The Past 20 years and Looking Forward. Oceanic Linguistics, Vol. 39, No.1, 157-169.

Rice, K. (2009). Must There Be Two Solitudes? Language Activists and Linguists Working Together. Indigenous language revitalization: encouragement, guidance \& lessons learned, stabilizing indigenous languages symposium (pp. 37-60). Arizona: Northern Arizona University.

Romereo-Little, M., McCarthy, T., Warhol, L., Zepeda, O., Ramanathan, V., \& Morgan, B. (2007). Language Policies in Practice: Preliminary Findings from a Large-Scale National Study of. TESOL Quarterly, 607-618.

Roskruge, M., Morrison, S., \& Maxwell, T. K. (2017). Measuring the value of the contribution of Māori language and culture to the New Zealand economy. Hamilton : Te Taura Whiri i Te Reo Māori.

Speas, M. (2009). Someone Else's Language: On the Role of Linguists in Language Revitalization. Indigenous language revitalization: encouragement, guidance \& lessons learned, stabilizing indigenous languages symposium (pp. 23-36). Arizona: Northern Arizona University . 
Te Rito, J. (2008). Struggles for the Māori language: He whawhai mo te reo Māori. MAI Review.

Waitangi Tribunal. (1989). Report of the Waitangi Tribunal on the te reo Maori claim 2nd edition. Wellington, New Zealand: Government Printer. 